\title{
DE BIBLIOGRAFÍA Y POESÍA: HERNANDO COLÓN Y SU LEGADO LITERARIO*
}

\author{
Ana M. Rodado RuIz \\ Universidad de Castilla - La Mancha \\ Ana.Rodado@uclm.es
}

L a obra poética conocida de Hernando Colón está integrada por 17 composiciones que fueron copiadas en los folios finales de uno de los cancioneros custodiados en la Biblioteca de la Universidad de Salamanca [SA10a]. Se trata de 16 canciones y un villancico conservados únicamente en este testimonio manuscrito. El hecho resulta extraño por la preeminencia de su autor, pero no lo es en el conjunto del cancionero pues SA10a transmite 51 textos únicos, un número muy elevado si tenemos en cuenta que son 75 las obras que integran la colección. Entre las piezas finales del cancionero se encuentran también cuatro obras anónimas que figuran a continuación de las composiciones de Colón: una de ellas — sin rúbrica - pertenece a Bartolomé de Torres Naharro; las tres restantes carecen por el momento de atribución plausible (Rodado Ruiz, en prensa). La peculiaridad de toda esta sección - incluidas las obras colombinas - es que esos unica (también la pieza de Torres Naharro) se fechan a principios del siglo XVI, media centuria después de la fecha probable de composición de las obras restantes.

En este trabajo analizaré algunos problemas en torno a la presencia de los poemas de Hernando Colón en este cancionero: de manera específica, nos detendremos en los aspectos relacionados con su localización dentro del repertorio - por la circunstancia de ser obras de cierre de un cancionero cuyo contenido remite

* Este trabajo se enmarca en el proyecto «Cancionero, romancero y fuentes impresas» del Ministerio de Economía, Industria y Competitividad (FFI2017-86313-P), financiado por la Agencia Estatal de Investigación (AEI) y el Fondo Europeo de Desarrollo Regional (FEDER), y dirigido por Josep Lluís Martos (Universidad de Alicante) como investigador principal. Como es habitual en los estudios sobre poesía de cancionero, me sirvo del sistema de siglas y de identificación de poemas empleados por Brian Dutton (1982; 1990-1991). SA10a es la sigla que Dutton asigna a la primera parte del manuscrito 2.763 de la Biblioteca Universitaria de Salamanca, que contiene el cancionero al que hago referencia.

Edad de Oro, XXXIX (2020), pp. 19-42, ISSN: 0212-0429 - ISSNe: 2605-3314

DOI: https://doi.org/10.15366/edadoro2020.39.001 
mayoritariamente a una cronología muy anterior-, aspectos fundamentales para estudiar el proceso de compilación y copia de la colección e intentar reconstruir el recorrido de la obra poética hernandina hasta esos folios de cierre del manuscrito. En la segunda parte del trabajo abordaremos el estudio literario y ecdótico para establecer la fijación textual ${ }^{1}$, más problemática de lo usual en tanto que son piezas de tradición monotestimonial.

\section{Los poemas de Hernando Colón en SA10A}

Comencemos por indagar las circunstancias que rodearon la composición y transmisión de los poemas colombinos. Hernando Colón es un poeta cortés tardío que no desmerece al lado de los vates de su entorno ${ }^{2}$ : como una más de sus aficiones humanísticas, cultiva la poesía en la que fue educado — canciones y villancicos como los que escuchó y leyó en la corte de los Reyes Católicos, en donde ejerció como paje del príncipe don Juan- y que se recogían en los cancioneros que se esforzó en adquirir para su biblioteca, como se verá más adelante.

Además de los problemas relativos a la fijación textual, y a la temática, retórica y métrica, de los que me ocupo más adelante, se nos plantean otras incógnitas en torno al corpus colombino, compacto y único - por diferentes motivos- dentro del cancionero salmantino. Cabría cuestionarse, en primer lugar, por qué escribe poesía amatoria Hernando Colón; o por qué no se conservan más testimonios de

De la obra poética colombina existen las ediciones de Harrisse (1871), Varela (1983), Dutton (1990-1991) y Díez Garretas (1994). La edición que aquí presento resuelve los problemas de los que adolecen las anteriores: la que ofrece Harrisse en un apéndice de su obra (a partir de la transcripción de Cayetano Rosell) fue pionera, pero ya está ampliamente superada debido al extraordinario desarrollo de los estudios sobre cancioneros castellanos y de la propia obra de don Hernando (sobre Harrisse y sus controvertidos méritos, véase Marín Martínez, 1970: 27-32); la de Dutton es también limitada por tratarse de una transcripción semipaleográfica; por último, frente a las de Varela y Díez Garretas (desiguales en calidad, pues la segunda enmienda con acierto defectos de la primera), el estudio ecdótico que presento me permite ofrecer un texto crítico depurado - libre de errores de transmisión - en el contexto de las obras que acompañan a la poesía de Colón en el cancionero salmantino (Rodado Ruiz, 2000a; 2016; 2017a; 2017b; 2018a; 2018b; en prensa).

2 No falta alguna descalificación, como la de Pedro Sainz Rodríguez en el prólogo al libro de Marín Martínez (XXVIII): «[...] los pocos y no muy valiosos versos de D. Fernando pertenecen a la poesía de metros tradicionales y gusto medieval». No nos sorprende el juicio peyorativo de este erudito; antes bien, hace consonancia con lo habitual hasta aquellas fechas en las valoraciones sobre la poesía cancioneril castellana (véase Whinnom, 1981: 9-11, que recoge las condenas de Menéndez Pelayo, Menéndez Pidal o Dámaso Alonso, entre otros). En líneas generales, es más frecuente encontrar juicios elogiosos sobre la faceta de biógrafo, cosmógrafo, bibliófilo y bibliógrafo de don Hernando, sobre su magnífica biblioteca y, por supuesto, sobre los diversos repertorios e índices que elaboró. Frente a la magnitud de tales aspectos, su legado literario parece cosa menor a los ojos de los estudiosos de la vida y obra colombinas. 
sus obras - siendo un bibliófilo concienzudo y esmerado- $-\mathrm{y}$ habiendo dispuesto de medios y oportunidad para encargar copias; o por qué se limitó a un repertorio tan escaso en número de piezas y en géneros, si es que solo escribió lo que se ha conservado (16 canciones y un villancico). En segundo lugar, convendría analizar por qué se copiaron estas obras en los folios finales del cancionero salmantino, repertorio que presenta una sorprendente similitud con un cancionero de la biblioteca hernandina hoy perdido; y aún más, cuándo y por qué se copiaron, a continuación de las de Colón, las cuatro obras anónimas finales, es decir, si es posible establecer vinculación entre ambas secciones en relación con el lugar y momento de la copia.

Sobre la primera cuestión, y a juzgar por lo que conocemos de su talante y biografía, no parece que el hijo del almirante se dedicara intensamente a pasatiempos líricos. Los documentos que se conservan sobre su vida y sus obras (Fernández de Navarrete, 1850; Hernández Díaz y Muro Orejón, 1941; Jos, 1945; Marín Martínez, 1970; Wagner, 1984, 1986 y 1992) nos brindan el retrato de un bibliófilo y bibliógrafo apasionado, interesado por la cosmografía, la biografía y la historia en general y, más en particular, por la figura de su padre, el almirante Cristóbal Colón, cuya crónica biográfica se ocupó en redactar (véase en la edición de Arranz, 1984). Fue un intelectual curioso: se educó junto a Pedro Mártir de Anglería, quien le inculcó el amor a los libros; además de la historia y el derecho —no en vano ejerció en ocasiones como jurista (Fernández de Navarrete, 1850: 298-483) - también le interesaban la literatura, la pintura o la música. Fue minucioso hasta el extremo, muy cuidadoso en sus disposiciones testamentarias en lo relativo a sus posesiones y, sobre todo, a su magnífica biblioteca (Hernández Díaz y Muro Orejón, 1941; Wagner, 1992). Según consta en su testamento, además de sus poemas en SA10a, dejó escritas dos inscripciones con fragmentos en verso (Hernández Díaz y Muro Orejón, 1941: 123-162; Varela, 1983: 188-190), que revelan detalles significativos en torno a la personalidad del autor. La primera inscripción estaba destinada a la fachada principal de su casa-palacio de Sevilla, en la que habría de conservarse su colección - aunque las cosas después no transcurrieran como él había dispuesto- y contiene una copla castellana, como las que usa en sus poemas. La segunda es un famoso epigrama latino en dísticos elegíacos para su lápida sepulcral ${ }^{3}$. Del orgullo que no ocultaba don Hernando por su ascendencia familiar y por su condición de bibliófilo dan fe sus indicaciones para los dibujos y el epitafio. Su atención al detalle y su carácter precavido se advierten en el aviso sobre la greca de follaje que proyecta como adorno, pues quiere «que no sea cosa sutil porque es de menos dura e la suciedad lo cubre más presto» (Varela, 1983: 189). El epitafio debía constar de tres cuerpos y en los tres queda

3 Véanse los textos de las inscripciones en el artículo de Varela (1983: 188-190).

Edad de Oro, XXXIX (2020), pp. 19-42, ISSN: 0212-0429 - ISSNe: 2605-3314 
constancia de sus preocupaciones o intereses: en el segundo debía esculpirse el escudo de la familia flanqueado por cuatro tablas o libros referidos a los catálogos de su biblioteca —autores, sciencie, epitome, materia - ; en el primero y tercero insiste en sus desvelos por acrecentar el saber [«haber despreciado mi ingenio las riquezas, / para abrirte a ti las divinidades de la fuente Castalia» (1983: 190)] y reclama la admiración y reconocimiento de la posteridad.

Esta extraordinaria minuciosidad en los detalles y la ponderación entusiasta de su oficio revelan una personalidad definida: Hernando Colón fue un humanista, un bibliófilo contagiado del espíritu del Renacimiento que había aprehendido en Italia, tierra que él conocía bien por sus continuos viajes en busca de libros a Génova, Venecia, Milán o Roma ${ }^{4}$. A juzgar por los títulos que compró y por sus disposiciones testamentarias en lo relativo a la continuidad de las adquisiciones de libros, concibe su biblioteca «sin distinción de ideologías e idiomas [...] una biblioteca del saber universal de su tiempo» (Wagner, 1992: 495) — pues no hubo restricciones temáticas, materiales, de precio o presentación (Álvarez Márquez, 2003: 64), ni en manuscritos ni en impresos - en la que llegó a reunir más de 15.000 volúmenes ${ }^{5}$, una proeza en su tiempo de la que se enorgullece siempre que encuentra oportunidad.

Así pues, a juzgar por el perfil intelectual descrito, es muy probable que la poesía fuera una ocupación meramente circunstancial en la vida del autor — quizá practicada solo en sus años de juventud-, aunque no fue un mal poeta: «atinado cultivador de la lengua castellana» lo llamó Amador de los Ríos (1865: 235), quien explicaba este interés de don Hernando por la poesía como un ejercicio propio de los cortesanos entre los que se educó en la corte de los Reyes Católicos, es decir, como influencia del entorno curial en el que vivió durante su adolescencia y juventud, tal como indiqué antes. Seguramente esa es la razón de su breve dedicación a la lírica y también la de que su obra quede limitada al cultivo de dos o tres géneros. En cambio, no casa bien con su personalidad el aparente desinterés por conservar su propia obra: no parece que proliferaran las copias o que se enviara a la imprenta, pues solo ha perdurado la versión manuscrita de SA10a. Naturalmente, es posible que todo sea consecuencia de desgraciadas pérdidas, pues los avatares del tiempo y el descuido con frecuencia afectan fatalmente a la frágil entidad de la poesía manuscrita o de los pliegos sueltos.

En todo caso, el interés del autor por la materia poética está fuera de duda. En las disposiciones sobre la compra de libros que figuran en su testamento, advierte

4 Entre 1512 y 1517 pasó largas temporadas en Roma, donde residía en el monasterio de observantes de San Francisco o de españoles. Recoge la noticia Wagner (1986: 714-715).

5 «[...] al menos 15.381 sin excluir la probabilidad de que fueran, si no muchos, sí algunos más» (Marín Martínez, 1970: 606). Sobre Hernando Colón y el proceso de creación de su biblioteca, véase el reciente libro de Wilson-Lee (2018), ya traducido al español (2019). 
a sus empleados «que no tomen ni escojan librero para proveerse de los [libros] gruesos e cavdalosos, lo vno porque no tratan ni curan de las obrezillas pequeñas ni de coplas e refranes e otras cosyllas que tanbién se an de thener en la librería» (Hernández Díaz y Muro Orejón, 1941: 154). Aunque esas «obrezillas de coplas e refranes» fueran seguramente impresos - objeto principal del interés del bibliófilo- compró también manuscritos; de hecho, especifica que «los que de mano se pudieren aver se comprarán por prescios moderados [...]» a condición de que «no los merquen por más prescio que valdrían de estanpa» (Wagner, 1992: 487) y, por supuesto, también aceptó muchos obsequios de libros (Wagner, 1986) ${ }^{6}$.

Sea como fuere, en los catálogos de su biblioteca figuran varios cancioneros de poesía contemporánea en castellano, en francés y en italiano ${ }^{7}$. Recuérdese que a medida que esta iba creciendo, Colón decidió elaborar distintos registros, concebidos en principio a manera de catálogos de adquisiciones, con el fin de no repetir ejemplares y de tener conocimiento de los volúmenes acumulados, así como de las materias que trataban. Ideó un innovador sistema de catalogación con varios tipos de repertorios de los que informa Juan Pérez, amigo personal y estrecho colaborador, en la Memoria que escribió tras la muerte del bibliófilo. Los que nos brindan más noticias sobre la poesía hernandina y su transmisión textual son el Registrum B, que recoge 4.321 asientos de libros comprados hasta 1530 , y el Abecedarium $B$, que contiene 15.344 registros alfabéticos de libros catalogados. También contienen noticias interesantes para nuestro propósito los repertorios de carácter documentalista de Materias y Proposiciones ${ }^{8}$.

En el Registrum $B$ figuraba un cancionero manuscrito de «diversos authores» cuyos nombres y obras se recogieron en latín en el libro de Materias. Este listado coincide en buena parte con el índice de autores y obras de SA10a ${ }^{9}$. La entrada del Registrum $B$ es la siguiente:

$6 \quad$ Álvarez Márquez estudia en detalle las adquisiciones de manuscritos que realizó el bibliófilo en distintas ciudades europeas y españolas (2003). No menciona ninguno de los cancioneros que figuran en el Registrum, conservados o perdidos, por no llevar nota de compra o adquisición.

7 Entre ellos, el Cancionero General de Hernando del Castillo, tan difundido en el siglo xvi que en vida de don Hernando se editó seis veces; raro sería que faltase un ejemplar en tan espléndida biblioteca.

8 Agradezco a los profesores Ruiz Asencio, Herrero Jiménez y Ruiz Albi, del Departamento de Paleografía de la Universidad de Valladolid, su gentileza al proporcionarme los materiales de los repertorios colombinos procedentes del proyecto de catálogo concordado, que esperamos pueda verse completado lo antes posible. Todas las citas de los repertorios proceden de dicha edición; hasta el momento solo se han publicado dos volúmenes (Marín Martínez, Ruiz Asencio y Wagner, 1993). También quiero hacer constar mi agradecimiento a la profesora Díez Garretas, de la misma universidad vallisoletana, por su generosidad y sus valiosas sugerencias.

9 Bartolomé J. Gallardo alude al cancionero de la biblioteca hernandina en su Ensayo, pero no tuvo acceso al manuscrito; los datos bibliográficos proceden de su transcripción del Registrum (1968 [1863-1889], II, col. 516), pues páginas atrás afirma que se perdió, es decir, no constaba en 
2054. [...] Cancionero de coplas de mano echas por diuersos authores. Al prinçipio está la tabla dellas juntamente con los authores. La primera obra comiença: No te remiembres, amor, de mis yerros ya pasados. La última acaba: que en la yglesia se canta ser su alma en paraýso. Est in folio, 2 columnarum.

La dispersión de muchos códices de la biblioteca colombina facilitaría, sin duda, la diáspora incontrolada de algunos de sus cancioneros, entre los cuales se encontraría el correspondiente al asiento 2.054 del Registrum B. Hasta el momento desconocemos si se vendieron libros para pagar deudas tras la muerte de Colón, de la misma manera que se vendieron bienes inmuebles, pero lo cierto es que se extraviaron no pocos ejemplares de la biblioteca original, que hoy se conserva considerablemente mermada ${ }^{10}$.

El listado en latín del libro de Materias proporciona los nombres de los poetas integrantes del cancionero perdido: Diego de Valera, Gómez Manrique, Pero Guillén, Diego de Burgos, Fernando de la Torre y Hernando Colón. Los autores coinciden con los de SA10a en número y secuencia, pero faltan algunos cuyas obras se copian entre las de los citados: Juan de Viana, Alonso de Lira, Juan de Torres, Juan Agraz, Alfonso Álvarez de Villasandino y Lope de Estúñiga, varios decires de Guillén, dos piezas anónimas y cinco introducciones en prosa a sendos textos; tampoco se mencionan las cuatro obras finales del manuscrito salmantino.

Por otro lado, el primer folio del cancionero SA10a plantea un nuevo interrogante a la problemática textual expuesta: ahí figura una tabla incompleta de autores y obras, ya que la última consignada es un decir de Pero Guillén, que no es

los fondos de la biblioteca colombina cuando él transcribió parte del Registrum, ya que dice lo siguiente a propósito de las obras en las que considera segura la autoría de don Hernando: «[...] sí consta de otras [obras] de que es autor, á saber, un Tratado de concordia, dedicado al cardenal Cisneros, y unas trovas, que con otras de otros ingenios forman un Cancionero manuscrito, que por desgracia ya no existe» (II, col. 511). Cuando Gallardo escribe su Ensayo, SA10a se guardaba en la Biblioteca del Palacio Real, adonde había llegado desde el Colegio Mayor de Cuenca en Salamanca.

10 Tras la muerte de Hernando Colón se efectuó el primer traslado de libros al monasterio dominico de San Pablo de Sevilla, después de que sus herederos pusieran a la venta la casa donde él había establecido su biblioteca. Desde allí, y tras pleito judicial, se llevaron al Cabildo de la catedral. Pero no queda constancia documental ni inventarios de dichos traslados, por lo que se desconoce cuántos libros pudieron desaparecer durante este proceso (Guillén Torralba, 2004: 255). Además, en 1558 la Inquisición de Sevilla efectuó un expurgo en la biblioteca y, algunos años después, en 1577 por orden de Felipe II, salieron de ella todos los libros sobre san Isidoro y probablemente algunos más, y se llevaron a El Escorial (Wagner y Guillén, 1990: 63-64). Esos libros nunca se devolvieron: «Pues ni los libros originales del Sr. San Isidoro que se llevaron a Madrid a petición del Sr. Felipe 2. ${ }^{\circ}$ para corregir por ellos los que se imprimían de que dio recibo a esta Santa Iglesia su Arzobispo el Sr. D. Christóval de Roxas y Sandoval [...] a quien no se han restituido los dichos originales, como ni otros muchos libros que faltan». Así lo manifiesta Juan de Loaisa en el prólogo de su «Abecedario de la Librería de la Santa Iglesia Catedral de Sevilla» de 1684 (Biblioteca Capitular y Colombina, ms. 82-5·28, 63). 
la última pieza del cancionero en su constitución actual. Además de algunas obras intermedias - que no coinciden por completo con las mencionadas antes como ausentes en el perdido cancionero de la biblioteca colombina - faltan en esa tabla dos obras de Estúñiga y una respuesta de Guillén, además del Combate de amor, las introducciones en prosa, una de las piezas anónimas, la sección de Colón y las cuatro obras finales.

Los datos expuestos se muestran claramente insuficientes para sustentar la hipótesis de que la entrada bibliográfica del Registrum a la que nos hemos referido pudiera corresponder a SA10a, no en su configuración actual sino en una fase de elaboración y copia anterior. El argumento más sólido que justificaría tal hipótesis es la coincidencia parcial en la selección y orden de los autores y obras antologados, pues, como se ha visto, en el libro de Materias de la biblioteca solo faltan los poetas de obra más breve (entre una y tres piezas), las introducciones en prosa (que tampoco figuran registradas en el índice inicial de SA10a, quizá simplemente por haber sido consideradas parte inicial o prólogo de cada composición) y las cuatro obras finales, que fueron copiadas por un distinto amanuense a continuación de la obra de Colón y, además, carecen de rúbrica de autor.

Como es lógico, coinciden ambos cancioneros en el incipit que se copia en la entrada del Registrum, pero no en el explicit, pues tales versos no constan sino en dicha entrada: ninguna composición los contiene como versos finales en los seis volúmenes del repertorio de Dutton (1990-1991). Una posible conjetura es que el manuscrito actual hubiera perdido algún folio antes de ser encuadernado junto a $\mathrm{SA} 10 \mathrm{~b}^{11}$, ya que la última pieza ocupa completamente la caja de escritura de la segunda columna en el $94 \mathrm{v}$, el folio final en la actualidad. Con todo, es sumamente improbable que un procedimiento de catalogación tan pormenorizado y preciso como el de los repertorios colombinos prescindiera del apunte correspondiente de varios autores y obras, por más que se tratara de autores de una o dos piezas, o de obras anónimas (perfectamente catalogables por la rúbrica o, en su defecto, por el incipit).

En trabajos anteriores he explicado mi hipótesis sobre la posibilidad de que SA10a sea la copia de un cancionero reunido por Pero Guillén de Segovia, en la que se habrían añadido algunas obras que no figuraban en el antígrafo (Rodado Ruiz, 2000a; 2017a; 2017b; véase también Moreno Hernández, 1989: 18-20). A partir de esta hipótesis y con los datos presentados, las noticias sobre los cancioneros relacionados con la obra de Colón presentan el siguiente balance:

11 SA10 es un códice facticio integrado por dos cancioneros independientes. 
A*) Primera compilación reunida por Guillén de Segovia (c. 1460-1465). Probablemente se cerraría con los Metros de los doce estados (SA10a-53) (Rodado Ruiz, 2017b: 221-222).

B) Cancionero de la biblioteca colombina, hoy perdido, y que figura en los repertorios con los asientos 2.054R (Registrum B), 3.583M (Materias), 2.995E (Epitomes) y con varias entradas por autores en el libro de Proposiciones.

C) Cancionero que contenía las obras que figuran en el índice inicial de SA10a y que le sirvió como modelo.

D) SA10a, que contiene las obras relacionadas en el índice más algunas añadidas, tanto en el interior del cancionero como al final, donde figura la sección de Hernando Colón.

El análisis codicológico y el estudio de la estructura y contenidos de SA10a (Rodado Ruiz, 2016; 2017a; 2017b) junto al cotejo de los índices de autores y obras de los dos manuscritos relacionados permiten proponer una hipótesis de transmisión: $\mathrm{B}, \mathrm{C}$ y $\mathrm{D}$ remontan en último término al arquetipo $\mathrm{A}^{*}$; $\mathrm{B}$ pudo ser copia directa de $\mathrm{A}^{*}$, en donde se añadieron los poemas de Hernando Colón en los folios en blanco al final del códice, un procedimiento que se repite en otros cancioneros, como advirtió Vicenç Beltran (1999: 45-48); C también tiene a A* como modelo, pero amplía el repertorio con una selección de obras de temática más cortesana, como son las piezas de Viana, Lira, Torres o Villasandino; finalmente, D (SA10a) contamina su modelo - que es C, pues ha copiado fielmente su índice- con nuevas piezas que abundan en la materia amatoria (Estúñiga, Guillén y Colón) y que alejan los temas del cancionero de la colectánea original, en la que predominan las obras de asunto moral o político. El artífice de SA10a - ya fuera el compilador o el cliente que encargó la copia - mandó incorporar esas piezas que le interesaban especialmente, es decir, las obras de SA10a que no figuran en la tabla inicial, y quizá cerró su cancionero con la obra poética hernandina. Es posible que fuera el ilustre bibliófilo el propietario ${ }^{12}$, y de ahí la copia de sus poemas, aunque los indicios no apuntan en esa dirección, pues las cuatro

12 Si observamos las rúbricas de las obras de don Hernando en busca de algún otro indicio, solo la primera obra contiene el nombre del autor: Cançion con su maldiçion fecha por don hernando colon. Resulta significativo que sea el único autor del cancionero cuyo nombre incorpora en una rúbrica el tratamiento deferencial reservado a nobles y altos prelados (no lo tienen las rúbricas de las obras de Gómez Manrique, por ejemplo), lo que permite pensar en la cercanía del rubricador, pero quizá solo se trate de un indicio más de respeto hacia el prestigioso bibliófilo. Las demás canciones y el villancico llevan rúbricas sencillas: cançion del mesmo, otra del mesmo, otra cançion del mesmo, villançico del mesmo. Lo más significativo es que no falta ninguna; en cambio, sí falta en la primera pieza copiada a continuación de las de Colón. 
obras finales remiten a un entorno italiano - tal vez napolitano- al menos para la selección y copia de esa sección última (Rodado Ruiz, en prensa).

Otra conjetura posible sería $\mathrm{A}^{*}=\mathrm{B}$ : es decir, que el hipotético cancionero reunido por Guillén de Segovia fuera el que figura en el Registrum de la biblioteca colombina, en donde se añadieron las obras de Colón ya en el siglo XvI, alejadas cronológicamente de las restantes piezas del repertorio.

SA10a formó parte de la biblioteca del Colegio Mayor de Santiago el Zebedeo, conocido como Colegio Mayor de Cuenca al haber sido fundado en el año 1500 por Diego Ramírez de Villaescusa, obispo de Cuenca y capellán mayor de los Reyes Católicos. No existen datos sobre los títulos o procedencia de los libros que sirvieron para constituir la biblioteca inicial pues los inventarios que se conservan son posteriores, pero con el tiempo se convirtió en la segunda biblioteca colegial más importante de Salamanca, después de la del Colegio de San Bartolomé (Carabias Torres, 1983: 145).

\section{ANÁlisis ECDÓtICO Y LITERARIO}

A diferencia de lo que ocurre con la obra de los otros autores antologados en SA10a, son escasos los errores de copia en las obras de Colón, más allá de ciertas ausencias de abreviatura de nasal o algún olvido que genera irregularidad métrica fácilmente enmendable, como veremos ahora; en cualquier caso, son menos numerosos que los de otros unica del cancionero ${ }^{13}$. Vamos a detenernos ahora en los casos de errores más relevantes con el fin de establecer el estado de los textos de cara a su estudio y edición; es preciso advertir que la obra de Colón se debe a un solo copista (cambian mano y grafía en las que le siguen). Distinguimos, en principio, entre errores mecánicos, debidos a olvidos o despistes del amanuense y que, por tanto, no tienen mayor interés al margen de apercibirnos de su usus scribendi; y errores de entidad morfológica, escasos, ya que el copista — el primero o algún otro copista o lector que haya revisado el texto - corrige algunos de esos despistes.

Entre los primeros casos, tenemos versos con ausencia de signos de abreviatura de nasal: por ejemplo, en los vv. 126 y 129 de la primera composición [ID1744] y en los vv. 5 y 14 de la cuarta [ID1747] y es dudoso en el v. 10 de la decimoséptima: planyr por plannyr / segud por segund / algud por algund / sy por syn. O tilde ociosa, como en 12, v. 4 (muncha).

Sorprenden dos únicos casos de seseo, que podrían hacernos pensar en un copista andaluz, ya fuera el de esta sección de SA10a o el de su modelo; nada

13 Especialmente abundantes son los errores en las obras de Pero Guillén de Segovia o en el Triunfo del Marqués de Diego de Burgos, aunque esta última obra no sea un unicum y su problemática sea diferente (Rodado Ruiz, 2017b). 
extraño, por otra parte, dado que don Hernando se estableció en Sevilla y allí se encontraban su biblioteca y su taller: así, en la primera canción se confunde «Z» con «S» en las palabras «maldezir/maldesir» y «aplazientes/aplasientes».

Más interesantes son los casos de errores morfológicos. En la siguiente canción - la undécima de la serie - la forma verbal «olbidas» no alude al Amor, como debió de pensar el copista, sino a uno de sus incautos seguidores y, por tanto, lo correcto es restituir la tercera persona. En el v. 11, la grafía produce confusión: considero que la forma «vencidos» es la que aparece en el manuscrito, como ya advirtió Díez Garretas (1994: 101), pero el copista olvidó la cedilla; de ahí que Dutton transcriba venados (1990-1991: IV, 228), forma que podría hacer sentido (el Amor nos vuelve locos, segunda acepción de «venados»), pero la rima lo desmiente:

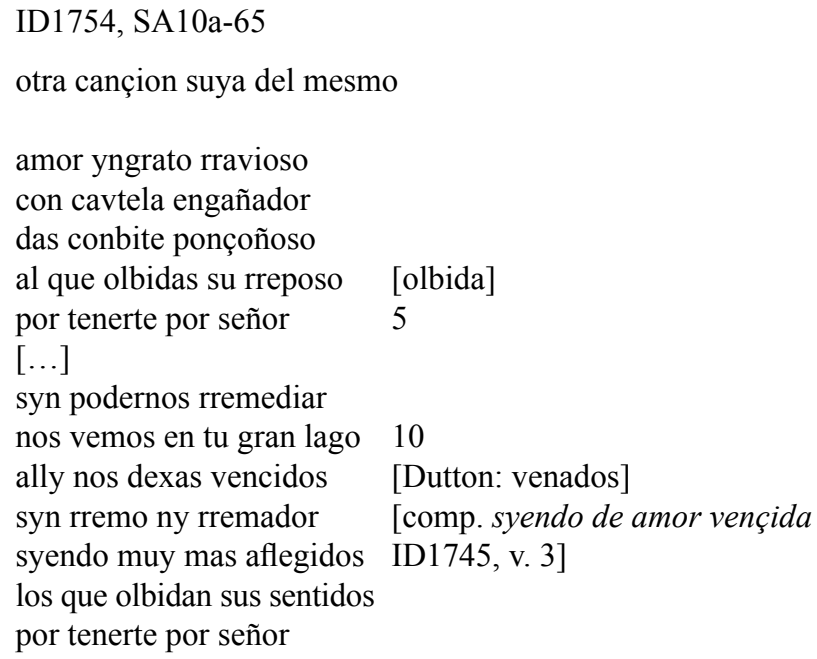

También encontramos otros errores de concordancia; en el siguiente ejemplo [ID1744], el copista advierte que, a diferencia del primer verbo en rima («falte») que remite a «guerra», el segundo, referido a «partes secretas», debería ir en plural; pero, bien él mismo, bien otra mano correctora, corrige y tacha la «n», al reparar en la exigencia de la rima en singular:

ID1744, SA10a-55

[...] las estrellas y planetas

nunca ya guerra les falte

y encontrandose muy rretas

las sus partes mas secretas

en pedaços se les salte(n\#) 
Algo similar ocurre en este otro error de concordancia, probablemente por olvido del signo de abreviatura nasal:

ID1746, SA10a-57

[...] por los ojos de la vida

pasa los del coraçón

los quales encandilados $[\ldots]$

muy mas quedan lastimados

Un caso diferente de tachadura y enmienda es el siguiente: Dutton consigna como (j\#:y) a lo que en el manuscrito figura al contrario; es decir, el copista escribe «y» y después enmienda en «j». En todas las ocasiones en que aparece el adverbio «jamas» en las obras de Colón, está escrito con «j»; solo en una ocasión figura escrito con «y», pero el sentido del verso obliga a transcribirlo como dos palabras (adverbios) distintas y separadas: «ya más».

ID1755, SA10a-66

[...] y asy me puso en olvido que (j\#:y)a mas non e podido pyadad de mi pedirle

ID1744

[...] que no puedo desamar ya mas de lo desamado

Otros errores importantes son los que producen hipometrías (I, v. 76; XV, v. 7, por ejemplo) e hipermetrías (I, v. 107, por ejemplo) respecto al octosílabo (7/9), especialmente por tratarse de textos únicos de difícil o arriesgada restauración. Obviamente, consideramos que los poetas son buenos rimadores: Hernando Colón lo es y observa la norma de respetar la regularidad del cómputo silábico (de hecho, es frecuente el uso de la diéresis, a veces doble en el mismo verso: «do jüez fue crüeldad», ID1745, SA10a-56, vv. 5 y 14); las alteraciones métricas han de responder, por tanto, a interferencias en el proceso de transmisión y copia, similares a las que producen otro tipo de cambios.

En alguna ocasión, palabras o versos aparentemente correctos no tienen sentido en la interpretación global de la estrofa en la que se insertan o lo hacen forzando la sintaxis (falta de preposiciones, usos no pronominales de verbos que lo son o que se emplean en esa forma [«soltó», por «se soltó», ID1755, v. 5], etc.). Como es obvio, la falta de otros testimonios dificulta la decisión crítica en la edición del texto. Ocurre, por ejemplo, cuando el pronombre no parece el más adecuado, como en los dos casos siguientes: 


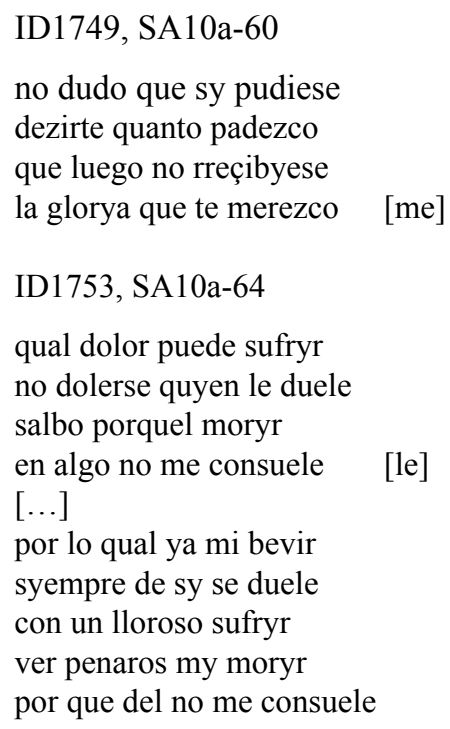

En el primer caso, el sentido de la estrofa exige el pronombre de primera persona en el último verso del estribillo. En el segundo poema, la pregunta impersonal de los dos primeros versos del estribillo (¿cuál sufrimiento [y por sinécdoque, ¿cuál amante dolorido?] puede soportar que no se compadezca la persona que provoca tal dolor?) no concuerda con el uso de la primera persona en el pronombre del último verso, ya que es en la mudanza y en la vuelta cuando se personaliza e individualiza el sufrimiento amoroso en la primera persona del poeta-amante.

Como en tantos otros poemarios del prerrenacimiento, la dama aludida en estos versos carece de rasgos individualizadores. No consta que existiera señora alguna a quien don Hernando dirigiera sus obras, pues nunca se casó ni quedó noticia tampoco de ninguna relación amorosa, así que se trata de piezas sin destinataria real conocida. Los textos discurren del elogio a la queja, sin traspasar los límites de los lugares comunes establecidos y consolidados. Con todo, entre las tópicas «llagas ponzoñosas» del amor (XIV, v. 2) y los lamentos del «triste dolorido» (XII, v. 6) se encuentran algunos destellos de originalidad retórica y métrica. Su estilo se caracteriza por un marcado hipérbaton y un acusado conceptismo con base en la elipsis, la traductio y el juego de contrarios ${ }^{14}$; así, entre el oxímoron y la paronomasia se configuran esos perfiles extremos de las «penas raviosas» del desamor (XIV, v. 5), aunque en el ámbito del sufrimiento no se enfrentan opuestos absolutos sino relativos. No se presenta el placer frente al dolor sino el dolor desgranado como único escenario posible y, en ese ámbito, distintos grados también

14 No falta tampoco algún latinismo léxico («ciente», v. 114). 
extremos: el sufrimiento frente a la desesperación, o bien, frente a la muerte, aunque esta tampoco traiga consuelo al poeta ${ }^{15}$.

Desde el punto de vista métrico es interesante la predilección del autor por el uso de la quintilla como estrofa. En la época de los Reyes Católicos, la canción adquiere una forma más o menos fija, compuesta por estribillo, mudanza y vuelta en versos octosílabos (Beltrán, 1988: 132). En los textos de Colón predominan los estribillos de cinco versos (once frente a cinco de cuatro versos); en la mudanza, cuya forma ortodoxa suele ser una redondilla, nueve canciones llevan quintilla; y en cuanto a la vuelta, además de los casos regulares de vuelta que repite la quintilla del estribillo, existen varias canciones con estribillos de cuatro y vuelta de cinco versos o viceversa. La mayor innovación, sin embargo, aparece en la primera composición; en primer lugar, por tratarse de una canción con dos vueltas (estribillo más dos estrofas); $\mathrm{y}$, en segundo lugar, porque a continuación, sin espacio físico de separación en el manuscrito, el autor continúa con un decir -a manera de desfecha, si no fuera por la extensión-, que se presenta como una «maldición» en doce coplas mixtas de nueve versos, en la que no solo cambia la estructura métrica sino también el desarrollo retórico y conceptual. La maldición como subgénero no resulta extraña en los cancioneros, en los que podemos encontrar conjuros contra el amor o contra la dama; no es frecuente, en cambio, que un decir para conjurar — en este caso, contra sí mismo, como automaldición — aparezca vinculado a una canción, por más que se trate de una canción de queja (el enlace es, precisamente, la palabra «maldezir»); no caben dudas sobre la estructura métrica de la pieza: la canción se compone de quintillas en todas sus partes, con retronx casi total del verso final del estribillo en las dos vueltas, mientras que el decir presenta una estructura de redondilla más quintilla $(4+5)$ y se cierra con una finida isométrica.

\section{Conclusiones}

La curiosidad intelectual de Hernando Colón le llevó a estimar de manera especial la creación lírica de su tiempo, a juzgar por los cancioneros y pliegos sueltos que reunió en su magnífica biblioteca; una modalidad literaria que él mismo practicó — seguramente con más dedicación durante su juventud- y por la que mostró

15 Las especificaciones temáticas del libro de Materias definen la poesía colombina íntegramente como poesía cortesana: versos dedicados a la descripción del fuego de amor, de las pasiones de los amantes y del poder del amor en la juventud: «Ferdinandus Colon, In variis cantilenis et rithmis hispanicis manuscriptis. Poesia humanitatis per totum est. Amatorios rithmos ad urbanum atque lepide amoris scintillas insinuandas per totum edidit. Amantium passiones quales sint diffuse detegit. Amoris imperium in adolescentes quantum sit diffuse detegit».

Edad de Oro, XXXIX (2020), pp. 19-42, ISSN: 0212-0429 - ISSNe: 2605-3314 
interés como lector y bibliófilo hasta el final de su vida, como demuestran sus disposiciones testamentarias.

Su obra poética se inscribe plenamente en la estética tardomedieval de la lírica cortesana. El joven don Hernando lee a sus contemporáneos y escribe como ellos, lo cual no impide atisbar en sus canciones y en su único villancico conservado ciertos visos de originalidad, muestra inequívoca de su interés por singularizarse. La temática amatoria no le facilitó la tarea - mucho menos en aquel momento en que el corpus de «cosas de amores» fue ciertamente abundante-, pero él se esforzó en buscar matices novedosos, experimentando con la métrica, la retórica y la fusión genérica (canción/decir-maldecir). En el aspecto métrico, prefiere el uso de la quintilla como estrofa, incluso en las mudanzas, cuya forma ortodoxa es la redondilla; en la retórica, le interesa la búsqueda del conceptismo con base en el hipérbaton, la paronomasia y el juego de contrarios.

Quiso la fortuna que la obra poética del bibliófilo cordobés quedase salvaguardada entre los folios de un cancionero manuscrito, cuya estructura y contenidos revelan distintas y complejas fases de gestación. Muchos interrogantes esperan aún respuesta, pero la transmisión textual de la poesía de Hernando Colón ha de vincularse necesariamente con la génesis y confección de SA10a y con su entorno —o entornos- de copia y recepción.

4. EDICIÓN $^{16}$

\section{I}

Canción con su maldición fecha por don Hernando Colón

¡Oh triste y oh desdichado! en desdichas muy dichoso, que me veo aprisionado do a mis penas y cuidado remedio pedir non oso.
Mi más raviosa ${ }^{17}$ pasión y muy crecida tristura, con muy sobrada razón, lastiman mi coraçón

10 por que os pida ya mesura ${ }^{18}$; mas el alto merecer y vuestro jesto ${ }^{19}$ gracioso me fuerçan a no creer ser igual ${ }^{20} \mathrm{mi}$ padecer,

16 Criterios de edición: me atengo a las normas actuales en la demarcación de palabras, puntuación, acentuación y en el uso de mayúsculas y minúsculas; respeto las vacilaciones gráficas del manuscrito, pero regularizo según los usos actuales las grafías $\langle\mathrm{i} / \mathrm{y} / \mathrm{j}\rangle,\langle\mathrm{u} / \mathrm{v} »$; indico las contracciones con un apóstrofo; resuelvo las abreviaturas sin indicación gráfica; restauro la «h» en las interjecciones; simplifico las consonantes dobles sin valor fonológico, pero respeto la ortografía de las oposiciones fonológicas medievales («b/v», «c-ç/z»), «x/j-g»), si bien transcribo siempre «c » ante vocal palatal («e», «i»), véase Álvarez Rodríguez (2006). Para las aclaraciones léxicas, me sirvo del Diccionario de la RAE o del Diccionario de Autoridades.

17 raviosa: «excesiva».

18 por que os pida ya mesura: «para que os pida compasión».

19 jesto: «rostro».

20 igual: «proporcionado o ajustado al alto merecer de la dama». 
$15 \mathrm{y}$ medio ${ }^{21}$ pedir non oso.

Y pues mi hadado 22 sino fue que yo sienpre padezca y cerró todo camino, porque mi triste venino ${ }^{23}$

20 ya jamás piadad merezca, quiero yo, triste, tomar para mi crudo reposo un penado sospirar con maldezir y llorar, pues medio pedir non oso.

\section{[Maldición] $^{24}$}

Maldigo quien m'engendró pues fue causa que padezca; quien de su lecho me dio crüel tormento merezca;

30 quien holgó porque nací mi tristeza le acompañe; la primer casa que bi, pues no cayó sobre mí, en vivas llamas se bañe.

35 La cibdad que me sostiene en abismo se convierta; la tierra, pues la mantiene, nunca esté salvo desierta; todas las aguas y fuentes

40 en hiel tornen su savor; los aires, muy aplazientes ${ }^{25}$, inflamados y hedientes ${ }^{26}$ se tornen sin resplandor.

El influxo y claridad

45 que de los cielos procede en tiniebla y tenpestad sïenpre, sin fin, se quede; las estrellas y planetas nunca ya guerra les falte,

$50 \mathrm{y}$, encontrándose muy $\operatorname{retas}^{27}$, las sus partes más secretas en pedaços se les salte ${ }^{28}$.

Los cielos muy acordados con su curso y armonía

55 humo se hallen tornados, y rigor y gran porfía; el mundo ya todo juncto totalmente se consuma, pues en él jamás un punto,

60 ni bien vibo ni defunto, a mis penas hallo suma ${ }^{29}$.

Mas, oh triste, ¿qué merecen los que culpa no me tienen? $?^{30}$ Mi cuerpo y vida se ofrecen

21 medio: «remedio».

22 hadado: «marcado por el destino adverso».

23 venino: «veneno»; metafóricamente, el amor.

24 En el manuscrito no figura ninguna indicación interestrófica; el anuncio de la «Maldición» solo aparece en la rúbrica.

25 aplazientes: «agradables, placenteros».

26 inflamados y hedientes: «calurosos y malolientes».

27 encontrándose muy retas: «aunque se encuentren en su lugar, en su trayectoria».

28 El sujeto exigiría la forma plural del verbo, pero la rima lo impide. Véase Aparato crítico.

29 [...] jamás un punto / [...] a mis penas hallo suma: «mis penas son tan excesivas que no pueden ser aumentadas, nada se puede añadir o sumar».

30 En las dos primeras estrofas del decir, el poeta maldice a sus padres por haberle engendrado, y maldice su casa y su ciudad, esto es, su entorno más cercano; en las dos siguientes, desea y convoca una suerte de apocalipsis: tinieblas, tempestades, destrucción de estrellas y planetas, y cataclismo total del mundo. A esto se refiere en la interrogación retórica de los vv. 62-63: ¿por qué castigar a los suyos o al mundo, si no son culpables? A partir de este momento, reconducirá su rabia y su necesidad de castigo y sufrimiento hacia sí mismo. 
65 a más mal del que sostienen; ellos huelgan de sofrir sobre sí toda querella, $\mathrm{y}$, muriendo, no morir ${ }^{31}$, y a pena penas pedir

70 por quien fue la causa d'ella.

Pues maldigo los cabellos que sobre mí, triste, nacen; sïerpes se tornen ellos, que mis carnes despedacen;

75 mis pies pisen por ladrillos brasas de biva llama; los mis dedos por anillos entre yunques y martillos como hierros tengan cama.

80 Si descanso me pidieren los mis miembros aflegidos, hállense por donde fueren de navajas muy ceñidos; mis uesos descoyuntados,

85 a tormentos doloridos y como vidro quebrados, hasta ser polbo tornados sean por sienpre molidos.

Los sentidos que poseo

90 tengan tan fuertes cadenas que jamás ni por deseo sientan salbante ${ }^{32}$ mis penas; mi fe se torne creer que mil penas más merezco;

95 mi esperança, un querer que jamás se pueda aver piadad porque padezco.
Amor me sea el raviar ${ }^{33}$, porque só tan desdichado

100 que no puedo desamar ya más de lo desamado; la prudencia, que querría que fuese de mi señora, es saver alguna vía

105 por do la gran pena mía se doblase en cada ora.

Jamás la mañanimidad que muestro con mi deseo la mude el adversidad

110 con que contino peleo; sea sienpre continente en descanso no pedir, $y$ justo con ser herviente en buscar muy más mi ciente ${ }^{34}$

115 forma de bibo morir.

El alma que me rovó quien contino me la tiene no se mude, pues halló mayor mal que jamás viene;

120 y pues sobra el merecer que merezco de penar, por momentos quiera ser mi pena doble en crecer y por mil mundos durar.

$$
\text { Fin }
$$

125 Porqu'el lloroso plañir y mi lengua muy turbada no me consienten pedir según mi deseo nada,

31 Nótese el políptoton — tan del gusto de Hernando Colón (cfr. v. 121)—, aquí en perfecta combinación con el oxímoron y la paronomasia.

32 salbante: «excepto».

33 El poeta desea que su amor sea el padecer («rabiar») puesto que no puede dejar de amar más de lo que ya desama, que no es nada a juzgar por su desesperación.

34 ciente: «que sabe, conocedora», pero aquí, «segura, inequívoca». El poeta se propone ser ferviente perseguidor de su muerte. 
a ti, profundo ${ }^{35}$ Señor,

130 a ti, fuente de saver, suplico con gran hervor pienses la pena mayor y esa me haz padecer.

\section{II}

\section{Canción del mesmo}

En peligro está la vida que perdió la livertad, siendo de Amor vencida en batalla tan reñida

5 qu'el jüez fue Crüeldad.

El penado coraçón tomó por armas mis ojos por vencer al afición que le da diez mil enojos;

10 mas vuestra gracia y figura, que puja toda veldad, hizo batalla más dura con armas de hermosura, do jüez fue Crüeldad ${ }^{36}$.

\section{III}

\section{Canción del mesmo}

Si tu gesto glorifica podiéndose contenplar, ¡oh triste!, que mortifica con el ver el desear.
5 Tu veldad es tan crecida y de tanta perfeción que, sin ser más detenida, por los ojos de la vida pasan los del coraçón;

10 los quales, encandilados de gloria tan singular, muy más quedan lastimados con el ver por desear.

IV

\section{Otra canción del mesmo}

Si sintiese que no peno por quien me causa penar, el morir abría por bueno o de mí no ser ajeno

5 algún consuelo tomar.

Porque es tal el merecer de quien abiva mi fuego que es gloria el padecer y pena todo sosiego;

10 por lo qual mi gran pasión es un medroso pensar: que no muera mi aflición o quiera mi coraçón algún consuelo tomar ${ }^{37}$.

35 profundo: «extenso, vasto», pero también «intenso e inescrutable».

36 Esta canción recrea la metafórica batalla librada entre el amante («la vida») y el amor; el poeta recurre a los tópicos órganos corporales («coraçón, ojos») para personificar el sentimiento. La dama responde ante el juez («Crüeldad») con «armas de hermosura» que, como es esperable, cautivan los ojos y estos rinden al «coraçón». La siguiente canción insiste sobre el mismo motivo. Colón se suma a las numerosas reelaboraciones del tópico del enamoramiento a través de los ojos, según la tradición italiana de raíz platónica; véase la obra de Marsilio Ficino (1986: VII, 4, 200-202), donde se encuentra la primera formulación del motivo; Baltasar de Castiglione (1984: IV, 7, 350); León Hebreo (1986: 201). Otros ejemplos de poetas del siglo xv se encuentran en Rodado Ruiz (2000b: 62-65); sobre su uso en la poesía del xvi y la explicación científica de la medicina de la época, véanse Prieto (1984: 246-247; 1986: I, 297-298).

37 El poeta expresa su deseo de vivir para sufrir, pues tal sufrimiento es placer y «gloria», ya que proviene de una dama de tan alto «merecer». 


\section{$\mathrm{V}$ \\ Otra canción del mesmo}

Aunque ya sin esperança tengo en vós mi fe vencida, la muerte de mi mudança sienpre muere con la vida.

5 La fe que tengo en amaros con coraçón abrasado, la fe de mi desearos con deseo apasionado, non espero que jamás

10 morirá tal fe vencida, aunque mi muerte verás morir sienpre con la vida ${ }^{38}$.

\section{VI}

Otra canción del mesmo

No dudo que si pudiese dezirte quánto padezco, que luego no recibiese la gloria que me merezco.

5 Si mi ravioso tormento füese de ti savido, aunque más desdeñamiento reinase tu pensamiento, sería luego vencido;

$10 \mathrm{y}$ de tal suerte, afligido, verías lo que padezco que no pusieses olbido en la gloria que merezco.

\section{VII}

Otra canción del mesmo

Un penado pensamiento no cesa de convatirme con tal rigor y tormento qual vuestro merecimiento

5 puso en vós mi fe más firme.

Y así se puede bien ver ser mi pena desigual pues que vuestro merecer no pudo jamás tener

10 salvo a ella por igual; por lo qual ya consolado no pienso jamás sentirme ni quiero verme librado de quien, sin duelo y cuidado,

15 puso en vós mi fe más firme ${ }^{39}$.

\section{VIII \\ Otra canción del mesmo}

¡Oh desdichado amador! ¡Oh triste de mi fortuna! Que me llaga cruel dolor y que fuese quiso Amor

5 sin esperança ninguna.

Mas si pienso de valerme y remediar mi pasión, aquello cabsa perderme sin fuzia de redención ${ }^{40}$; 10 porque la llama de amor

\footnotetext{
38 Juego extremo con el políptoton para expresar la fortaleza de la fe del poeta-amante: la vida vence a la muerte y, por ello, no es posible su «mudança», el vencimiento de su fe.

39 [...] ni quiero verme librado / de quien [...] / puso en vós mi fe más firme: es decir, no quiere verse librado de su «penado pensamiento».

40 fuzia: «confianza»; redención: «remedio». Cpse. XVII, v. 10.
} 
más abrasa si se inpuna ${ }^{41}$, y piensa ser vencedor quien abiva su dolor sin esperança ninguna.

\section{IX}

Otra canción del mesmo

Pues sin causa só culpado y peno por merecer ¡oh, muerte de mi cuidado! ¿por qué me as olbidado

5 $\mathrm{y}$ no me quieres valer?

Müerte, quien no conoce el descanso que acarreas como de cruda y feroce teme tus graves peleas;

10 mas a mí que tu memoria descansa mi padecer, dame parte de tu gloria y no turve tu vitoria que no me quieres valer ${ }^{42}$.

\section{$\mathrm{X}$}

Otra canción del mesmo

¿Quál dolor puede sufrir no dolerse quien le duele, salbo porqu'el morir en algo no le consuele?
5 Yo padezco por quereros, y vós, porque yo padezca; yo muero por mereceros, y vós, porque n'os merezca, por lo qual ya mi bevir

10 sïempre de sí se duele con un lloroso sufrir: ver penaros mi morir por que d'él no me consuele ${ }^{43}$.

\section{XI \\ Otra canción del mesmo}

5 por tenerte por señor.

Con tu vista singular nos convidas con halago: de que pensamos gozar, sin podernos remediar,

10 nos vemos en tu gran lago; allí nos dexas vencidos sin remo ni remador, siendo muy más aflegidos los que olbidan sus sentidos 15 por tenerte por señor ${ }^{44}$.

41 inpuna: «combate».

42 En esta canción, al contrario que en las precedentes, el poeta-amante reclama la muerte de su «cuidado» o aflicción.

43 Magnífica canción en la que el poeta demuestra su destreza en el manejo de la figura etimológica o políptoton y del juego conceptista. El estribillo presenta una cuestión impersonal acerca del dolor que no recibe compasión por parte de la persona que lo provoca, a manera de concitación del poeta a una reflexión sobre la magnitud de tal dolor, que solo se alivia con la muerte; la mudanza y la vuelta individualizan el caso: la tercera persona deja paso a la primera y el poeta-amante confiesa, en un alarde conceptista, que la muerte (hiperbólica, es decir, el sufrimiento), única fuente de consuelo ante la falta de compasión, deja de serlo si la dama, finalmente, se compadece. Incluso podría haber una posible alusión al fingimiento de la dama para provocar un dolor mayor al amante: ella se duele de su sufrimiento para que él no encuentre consuelo ni siquiera en el dolor.

44 los que olbidan sus sentidos: «quedan más dañados los que no se aperciben del engaño». Esta canción y la siguiente se dedican al amor y su proverbial carácter falaz: atrapa a los incautos y paga mal a sus fieles servidores. 
XII

Otra canción del mesmo

El pago que Amor ordena

a quien más suyo se dio es una triste cadena, labrada de mucha pena, 5 do jamás nadie soltó.

Allí triste, dolorido, me prendió por bien serbirle, y así me puso en olvido que jamás non e podido

10 piadad de mí pedirle; y esto de cierto cabsó tenerme por muy leal, porque quien es así tal nunca jamás lo soltó.

\section{XIII}

Villancico del mesmo

Llora, triste coraçón, sin cesar, que razón as de llorar.

Llora mi triste ventura

5 pues que amo sin medida do solamente tristura es galardón de mi vida; de tanta pena vencida, sin cesar,

10 que razón as de llorar.

Llora, que huye mi muerte quanto más triste la sigo, y que otra, muy más fuerte, traigo por siempre comigo

15 con tal pasión que te digo, sin cesar, que razón as de llorar.
XIV

Canción del mesmo

$¡$ Ay, que soy lastimado de llaga tan ponçoñosa que da bivir conpasado ${ }^{45}$ quanto pueda mi cuidado

5 sufrir su pena raviosa!

Es tan cruda la pasión de que só triste, herydo, que seso ni discrición algún consuelo no son

10 del coraçón aflegido; porque amor con desamor me muestra cara sañosa y, por darme más dolor, dame vida por amor

15 que sufra pena raviosa.

\section{$\mathrm{XV}$ \\ Otra del mesmo}

¡Oh dicha ciega, malvada, con errores siempre llena! Jamás visitas posada do eres más obligada, $5 \quad$ y pasan por ti gran pena.

Los que muy más descuidados biven sin tu deseo, aquellos más visitados y de ti más sublimados

10 yo siempre jamás los veo; mas a mí que te merezco, por tener brava cadena, diez mil tormentos padezco pasando por ti gran pena ${ }^{46}$.

45 conpasado: «al compás del sufrimiento». Cpse. XVII, v. 9.

46 El poeta se queja de que la dicha, como el amor (cpse. XI, XII), huye de quien más la merece. 
XVI

Otra canción del mesmo

Amor me manda sofrir; la pena, que desespere, así que mi vida muere sin saber a quál seguir.

5 Tan cativo mi deseo tengo en vós, triste, cuitado, que más mal del que me veo tiene por bien enpleado ${ }^{47}$; mas la pena desigual

10 que vós me causáis sofrir desespera con mi mal, así que bivo mortal sin saber a quál seguir.
XVII

Otra canción del mesmo

Mil vezes desesperança a la muerte me convida, y tantas hago mudança con penada confiança

5 qu'os doleréis de mi vida.

Mas ya qu'están desplegadas las velas de mi pasión, y para siempre selladas mis cuitas acostunbradas

10 sin fuzia de redención, suelte sus riendas la muerte sin dilatar su venida, y fenezca ya mi suerte feneciendo con la vida.

\section{Aparato CRítico}

I. 9 coraçón ] coracon SA10a $\mid 24$ maldezir ] maldesir SA10a $\mid 41$ aplazientes ] aplasientes SA10a 52 salte ] salten (tachada la $n$ ) SA10a | 125 plañir ] planir SA10a $\mid 128$ según ] segud SA10a.

III. 9 pasan ] pasa SA10a.

IV. 5 algún ] algud SA10a 14 algún ] algud SA10a.

VI. 4 me ] te SA10a.

X. 4 le ] me SA10a.

XI. 4 olbida ] olbidas SA10a.

XII. 4 mucha ] muncha SA10a.

XIV. 9 algún ] algund SA10a.

XV. 13 mil ] mill SA10a.

XVII. 1 Mil ] mill SA10a.

\section{BibLIOGRAFÍA}

Álvarez Márquez, Carmen (2003). «El itinerario de adquisiciones de libros de mano de Hernando Colón». Historia. Instituciones. Documentos, 30, pp. 55-102.

Álvarez Rodríguez, Adelino (2006). «Los resultados hispanos del grupo latino $s c$ ante vocal palatal». Revue de Linguistique Romane, 279-280, pp. 351-376.

Amador de los Ríos, José (1865). Historia crítica de la literatura española. Madrid: Imprenta de Joaquín Muñoz, t. VII.

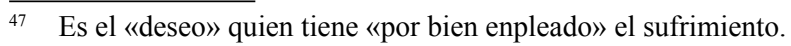

Edad de Oro, XXXIX (2020), pp. 19-42, ISSN: 0212-0429 - ISSNe: 2605-3314 
Arranz, Luis (ed.). Véase Colón.

Beltrán, Vicente (1988). La canción de amor en el otoño de la Edad Media. Barcelona: Promociones y Publicaciones Universitarias.

BeLtran, Vicenç (1999). «Tipología y génesis de los cancioneros: la organización de materiales». En Vicenç Beltran et alii (coord.), Estudios sobre poesía de cancionero. Noia: Toxosoutos, pp. 9-54.

Castiglione, Baltasar de (1984). El cortesano. Rogelio Reyes Cano (ed.). Madrid: EspasaCalpe.

Colón, Hernando (1984). Historia del Almirante. Luis Arranz (ed.). Madrid: Cambio 16.

Díez Garretas, M. ${ }^{a}$ Jesús (1994). «La cortesía de don Fernando Colón». En El reino de Granada y el Nuevo Mundo. V Congreso Internacional de Historia de América (Granada, mayo de 1992). Granada: Diputación Provincial de Granada, pp. 83-103.

Dutton, Brian (1982). Catálogo-índice de la poesía cancioneril del siglo XV. Madison: Hispanic Seminary of Medieval Studies.

Dutton, Brian y Jineen Krogstad (eds.) (1990-1991). El cancionero del siglo XV, c. 13001520. Salamanca: Universidad de Salamanca («Biblioteca Española del Siglo XV», Serie Maior, 7).

FernÁNDEZ de NAVARRETE, Eustaquio (1850). «Noticias para la vida de don Hernando Colón». En Colección de Documentos Inéditos para la Historia de España. Madrid: Imprenta de la Viuda de Calero, t. XVI.

Ficino, Marsilio (1986). De Amore. Comentario a «El Banquete» de Platón. Rocío de la Villa Ardura (trad. y ed.). Madrid: Tecnos.

Gallardo, Bartolomé José (1968). Ensayo de una biblioteca española de libros raros y curiosos, ed. facsímil [1863-1889]. Madrid: Gredos, t. II.

Guillén de Segovia, Pero (1989). Obra poética. Carlos Moreno Hernández (ed.). Madrid: Fundación Universitaria Española.

Guillén Torralba, Juan (2004). Hernando Colón: humanismo y bibliofilia. Sevilla: Fundación José Manuel Lara.

Harrise, H. (1871). Don Fernando Colón, historiador de su padre. Ensayo crítico. Sevilla: Sociedad de Bibliófilos Andaluces.

Hebreo, León (1986). Diálogos de amor. Andrés Soria Olmedo (ed.), David Romano (trad.). Madrid: Tecnos.

Hernández Díaz, José y Antonio Muro Orejón (1941). El testamento de Hernando Colón y otros documentos para su biografia. Sevilla: Publicaciones del Instituto HispanoCubano de Historia de América / Fundación Rafael G. Abreu.

Jos, Emiliano (1945). Investigaciones sobre la vida y obras iniciales de don Fernando Colón. Sevilla: Escuela de Estudios Hispanoamericanos.

Marín Martínez, Tomás (1970). Obras y libros de Hernando Colón. Madrid: Imprenta del Consejo Superior de Investigaciones Científicas de Sevilla.

Marín Martínez, Tomás, José Manuel Ruiz Asencio y Klaus Wagner (1993). Catálogo concordado de la Biblioteca de Hernando Colón. Madrid: Fundación Mapfre América / Cabildo de la catedral de Sevilla.

Moreno Hernández, Carlos (ed.). Véase Guillén de Segovia.

PRIETO, Antonio (1984). La poesía española del siglo XVI. Madrid: Cátedra, t. I. 
Prieto, Antonio (1986). La prosa española del siglo XVI. Madrid: Cátedra, t. I.

Rodado RuIz, Ana M. (2000a). «Notas para la edición de SA10». En Margarita Freixas, Silvia Iriso y Laura Fernández (eds.), Actas del VIII Congreso Internacional de la Asociación Hispánica de Literatura Medieval (Santander, 22-26 de septiembre de 1999). Santander: Consejería de Cultura del Gobierno de Cantabria, t. II, pp. 1.547-1.557.

Rodado Ruiz, Ana M. (2000b). Tristura conmigo va. Fundamentos de amor cortés. Cuenca: Universidad de Castilla - La Mancha.

Rodado Ruiz, Ana M. (2016). «El Cancionero Antiguo de Salamanca (SA10a): materiales de un códice de poesía medieval». eHumanista. Journal of Iberian Studies, 32, Monographic Issue. Codicología y Bibliografia: Cancionero y Romancero. Josep Lluís Martos (coord.), pp. 361-373.

Rodado Ruiz, Ana M. (2017a). «Poesía única y deturpación textual en SA10a». En Josep Lluís Martos (ed.), Variación y testimonio único. La reescritura de la poesía. Alacant: Universitat d'Alacant.

Rodado Ruiz, Ana M. (2017b). «Variantes, variaciones e imprenta: SA10a y 11CG». Revista de Literatura Medieval, XXIX, pp. 197-223.

Rodado Ruiz, Ana M. (2018a). «Un decir de atribución dudosa: el Combate de amor [ID1731]». En Andrea Zinato y Paola Bellomi (eds.), Poesía, poéticas y cultura literaria. Como / Pavia: Ibis, pp. 201-211.

Rodado Ruiz, Ana M. (2018b). «"Venid, amadores, veréis maravilla”: el Combate de amor del Cancionero General». Cultura Neolatina, LXXVIII, 3-4, pp. 239-274.

Rodado RuIz, Ana M. (en prensa). «Los poemas finales de SA10a: edición crítica y estudio literario»». En Actas del XVIII Congreso Internacional de la Asociación Hispánica de Literatura Medieval.

VARELA, Consuelo (1983). «La obra poética de don Hernando Colón». Anuario de Estudios Americanos, XL, pp. 185-201.

WAGNER, Klaus (1984). «El itinerario de Hernando Colón según sus anotaciones. Datos para la biografía del bibliófilo sevillano». Archivo Hispalense, 203, pp. 81-99.

WAGNER, Klaus (1986). «Libros obsequiados a Hernando Colón y otras curiosidades de su biblioteca». En Homenaje a Pedro Sainz Rodríguez. Madrid: Fundación Universitaria Española, t. III, pp. 713-724.

WAGNER, Klaus (1988). «Libros de la biblioteca colombina perdidos y hallados». Journal of Hispanic Philology, XIII, pp. 7-11.

Wagner, Klaus (1992). «La biblioteca colombina en tiempos de Hernando Colón». Historia. Instituciones. Documentos, 19, pp. 485-495.

Wagner, Klaus y Juan Guillén (1990). «Pasado, presente y futuro de la Biblioteca Colombina». Minervae Baeticae, XVIII, pp. 61-77.

Whinnom, Keith (1981). La poesía amatoria de la época de los Reyes Católicos. Durham: University of Durham.

Wilson-LeE, Edward (2019). Memorial de los libros naufragados. Hernando Colón y la búsqueda de una biblioteca universal [2018]. M. a Dolores Ábalos (trad.). Barcelona: Ariel.

Recibido: 05/11/2019

Aceptado: 12/03/2020

Edad de Oro, XXXIX (2020), pp. 19-42, ISSN: 0212-0429 - ISSNe: 2605-3314 


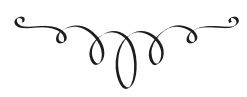

De bibliografía y PoEsía: Hernando Colón y su legado literario

RESUMEN: La obra poética de Hernando Colón está integrada por 17 composiciones que figuran, en versión única, en los folios finales de uno de los cancioneros custodiados en la Biblioteca de la Universidad de Salamanca [SA10a, Ms. 2763]. En este trabajo analizo algunos problemas en torno a la edición de los poemas de Hernando Colón, edición que se ofrece como apéndice: de manera específica, se estudian las dificultades de fijación textual derivadas de su condición de piezas de tradición monotestimonial, así como también los aspectos relacionados con su ubicación dentro del repertorio, por la circunstancia de ser obras de cierre de un cancionero cuyo contenido remite mayoritariamente a una cronología anterior.

Palabras Clave: Hernando Colón, poemas únicos (unica), cancioneros manuscritos, poesía medieval castellana, SA10a.

\section{BiBliography AND POETRY: HeRNANDO COLÓN AND HIS LITERARY LEGACY}

AвSTRACT: The poetic work of Hernando Colón consists of 17 compositions that appear, in unique version, in the final folios of the manuscript songbook SA10a (Ms. 2763, Library of the University of Salamanca).This paper focuses on the analysis of some problems about the localization and editing of these poems, and it offers a critical edition of them; specifically, the article studies the difficulties of textual transmission, as pieces of monotestimonial tradition, and another aspects related to their location at the end of the Salamanca's songbook, a collection that contains mostly works belonging to the Xvth century.

KeYwords: Hernando Colón, Unique Poems (unica), Manuscript Songbooks, Spanish Medieval Poetry, SA10a. 